\title{
LA EXCLUSIÓN RESIDENCIAL Y EL DESARROLLO DE LA CIUDAD MODERNA EN AMÉRICA LATINA: DE LA POLARIZACIÓN A LA FRAGMENTACIÓN. EL CASO DE SANTIAGO DE CHILE ${ }^{1}$
}

\author{
Rodrigo Hidalgo D. ${ }^{2}$ y Axel Borsdorf M. ${ }^{3}$
}

\begin{abstract}
Resumen: Aparentemente los conjuntos residenciales con acceso exclusivo para sus residentes son un nuevo fenómeno en las ciudades latinoamericanas. Sin embargo, la evolución urbana de los países de la región expresa una constante aparición de barrios separados del resto del complejo urbano en el que se construyen. No solamente habitados por las elites y distribuidos por diversas localizaciones, con distinta base social y territorial, en las últimas décadas, con la irrupción del neoliberalismo y la globalización, ellos aumentaron significativamente su tamaño, superficies y número de habitantes.
\end{abstract}

Palabras clave: barrios cerrados, fragmentación urbana, geografía urbana.

\begin{abstract}
At first sight, exclusive residential complexes with restrictive access seem to be a new phenomenon in the Latin American cities. Yet, the urban evolution of the countries of the region exhibit a pattem of districts separated from the rest of the urban complex in which they are entangled. During the last decaldes and along with the irruption of neoliberalism and globalization, these living spaces covered different areas and accommodated diverse social sectors, not only elites; increasing significantly their size, surfaces and number of inhabitants.
\end{abstract}

Key words: gatted comunnities, urban fragmentation, urban geography.

\footnotetext{
1 Proyectos Fondecyt 1030472,7040113 y: 7050123

2 Instituto de Geografía, Pontificia Universiclad Católica de Chile.

3 Instituto para la Investigación Urbana y Regional, Academia de Ciencias Austriaca, Vienna y Instituto de Geografía, Universidad de Innsbruck, Austria.
} 
En América Latina los conjuntos de viviendas con accesos controlados, conocidos como barrios cerrados, aparecen como un fenómeno que cobró importancia en las últimas décadas. Precisamente en dicha región, ellos, junto a otros hitos característicos de la ciudad postmoderna, como las autopistas urbanas, centros comerciales de grandes superficies y parques tecnológicos, son indicados como los elementos más relevantes del nuevo modelo de la estructura y el desarrollo urbano latinoamericano (Borsdorf 2003a e Hidalgo y Borsdorf, 2005).

En este contexto los barrios cerrados son vistos como un fenómeno reciente, cuya difusión estaría apoyada en la hegemonía del paradigma de desarrollo económico neoliberal y el proceso de globalización, expresados en las últimas décadas en transformaciones tan profundas como la retirada del Estado, disminución de los servicios públicos y flexibilidad de los instrumentos de planificación del uso del suelo (Harvey, 1990, Marcuse y Kempen, 2000).

Esta hipótesis es especialmente válida para aquellas agrupaciones residenciales cerradas aparecidas en los últimos años, cuyo tamaño ha ido en progresivo aumento hasta convertirse en verdaderas ciudadelas. Ellas poseen ciertas características que son comunes, tanto en su diseño como localización al interior y exterior del organismo urbano. Alto despliegue en materia de seguridad e intervenciones de gran tamaño ubicadas en la periferia de las ciudades son símbolo de la globalización, que, en este caso, se expresa en un sector inmobiliario que reproduce pautas similares de producción y consumo en los distintos países latinoamericanos (Borsdorf e Hidalgo, 2004, Meyer y Bähr, 2004, Janoshka y Borsdorf, 2005).

Las formas tempranas de exclusión residencial vinculadas a lo que hoy podríamos llamar como barrios cerrados se encuentran en las bases de la ciudad polarizada, donde ricos y pobres habitaban en sectores muy bien definidos. Por su parte los nuevos emprendimientos de un gran número de viviendas y población considerable, más de 50.000 habitantes para el caso de las ciudades valladas en Chile (Borsdof e Hidalgo, 2004 a), marcan un nuevo estadio en la distribución espacial de las clases sociales, donde los grupos medios y medios altos en su búsqueda de exclusividad a la usanza de la elite los lleva a dispersarse, en muchos casos concentradamente, por distintos puntos de los bordes de las metrópolis (Hidalgo y Borsdorf, 2005). Su producto es la ciudad fragmentada, donde la posición social ya no determina la ubicación geográfica, existiendo una verdadera imbricación socioespacial, cuya expresión material se manifiesta en diferencias que se ven incrementadas por la proximidad de los distintos grupos o tipos de habitantes (Prêvot, 2000). A su vez y aunque suene paradójico, la fragmentación permite establecer un vínculo entre las dinámicas espaciales ligadas a la metropolización -expansión, movilidad, surgimiento de nuevas centralidades- y el estallido de la unidad, resultante de la agravación de las desigualdades sociales, de las formas de desolidarización y de los reagrupamientos por afinidades (Prêvot, 2002). 
En este contexto, el presente artículo ${ }^{4}$, basado en el caso de Santiago de Chile, intenta interpretar como los barrios cerrados han marcado el desarrollo de la estructura de la ciudad latinoamericana, desde su nacimiento hasta nuestros días, con distintos estadios, magnitudes y expresiones en la geografía social de la ciudad. Se postula que para una comprensión integral del fenómeno contemporáneo de los barrios cerrados, el análisis debe considerar aquellos factores que tienen relación con la tradición urbana de la región, que muestra una práctica constante por parte de determinado segmento de la sociedad citadina a encapsularse en sus lugares de residencia (Borsdorf, 2002 y Borsdorf e Hidalgo, 2004). En este escenario cabe preguntarse cuales son la formas que antecedieron a los mega barrios cerrados o ciudades valladas que se construyen en la actualidad en la periferia de las principales capitales latinoamericanas y como este tipo de residencias fue evolucionando en el tiempo, así como los factores más significativos que desencadenaron su aparición.

\section{Las primeras formas de exclusión: las viviendas de la ciudad colonial}

Las viviendas de las ciudades iberoamericanas fundadas bajo las leyes de Indias contemplaron accesos directos desde la calle, pero tuvieron elementos de separación con ella, existiendo una clara delimitación entre la propiedad privada y el espacio público (Ramírez, 1993). Importadas desde Europa y por extensión solidarias de la tradición grecorromana de la cual fueron herederas, las viviendas de las élites se construyeron en las manzanas o cuarterones mejor ubicados de la cuadricula ortogonal.

En México las casas de la elite fueron construidas de cal y piedra, empleándose fosos y a veces torreones para su protección. Por su parte, los vecinos españoles, criollos y mestizos, vivieron en albergues cerrados que fueron al mismo tiempo hogar y negocio. Las casas no solo se edificaron en forma horizontal sino que también vertical, con más de un piso o nivel. En las viviendas de mayor alcurnia, las plantas bajas cumplieron la función comercial o de pequeña factoría, mientras que en las más populares la parte interior sirvió de habitación y la que miró a la calle fue destinada a tiendas o talleres (González, 1993).

En este mismo país, los espacios internos de la vivienda no sólo mostraton una diferenciación funcional, sino que también fueron habitados por más de un grupo familiar y se distinguieron en su ocupación vertical. En este sentido en las casas altas existía una autonomía y especialización de las habitaciones, existiendo por lo tanto, la posibilidad de tener intimidad en el interior de la vida familiar (López, 2001).

4 Los resultados son parte de los proyectos Fondecyt 1030472 y 7040113. 
En Chile, con desfases y atemporalidades respecto de otras regiones del continente (Sahadi, 1994) la tipología colonial está representa por la casa de tres patios (Revista CA, 1978). El acceso fue por un amplio portón, en el cual se abría un pequeño "postigo", de uso más cotidiano. Por un ancho zaguán se entraba a un primer patio, al cual desembocaban las bodegas, y en algunos casos las habitaciones de alquiler. Entre este primer patio y el segundo, estaba el salón y lás habitaciones privadas de la vivienda, lugar en el que también se encontraban los jardines principales. El tercer patio muchas veces era destinado al huerto y las habitaciones que daban a él eran habitadas por la servidumbre. Hacia la calle en algunas viviendas había un cuarto que en algunas ocasiones se destinaba al comercio y junto al zaguán se disponía de un cuarto para el llavero (León Echáis, 1974).

Mientras que algunos autores frecuentemente identifican el principio español de refrigeración vía acumulación del frío en muros sólidos como responsable para aquelia estructura, los portugueses prefrieron el principio de refrigeración por la corriente de aire, a través de aperturas de los muros estructurales (Borsdorf y Stadel 2001). Sin embargo, el método del enfriamiento puede ser considerado una consecuencia de la demanda de los ciudadanos por privilegiar un ámbito familiar con cierto grado de intimidad. En este sentido, la tendencia de segregación es, en cierto modo, marcada, no solamente con el mundo exterior, sino también hacia adentro (Wilhelmy y Borsdorf, 1984). Ello queda representado por diferentes lugares de la casa que son asignados específicamente a personas o familias que desarrollan funciones de servicio o corresponden a espacios destinados a los huéspedes. Dichas viviendas no conformaron barrios cerrados en la definición actual, sin embargo ellas se diseñaron con accesos separados, a los cuales solo tenían entrada determinados individuos (Borsdorf e Hidalgo, 2004).

Además existieron en la ciudad colonial otros barrios cerrados, accesibles solamente para ciertas personas. La ciudad monasterial de Santa Catalina en Arequipa, Perú, el seminario de la Compañía de Jesús en Tepotzotlán, o el Hospitolio Cabañas en Guadalajara, aparecido en el siglo XIX, son ejemplos de barrios de amplio tamaño, que fueron cerrados y designados para señoras, viudas, seminaristas o huérfanos. En este sentido aún el mismo monasterio puede ser interpretado como un barrio cerrado temprano.

\section{Los company-towns y las viviendas obreras como barrios cerrados en el siglo $\mathrm{XIX}$}

Con una relevante presencia de empresarios ingleses y norteamericanos, en América Latina el desarrollo de la minería dio lugar a asentamientos que en muchos casos fueron amurallados y equipados con barreras. En México, Argentina, Brasil, Perú y Bolivia, entre los más significativos, en las distintas fases de su evolución his- 
tórica, existieron los company-touns o pueblos de las compañías, que estuvieron destinados a los empleados y trabajadores de compañías mineras o industriales. Se ubicaron cercanos a los yacimientos o en la periferia de los pueblos o ciudades próximos a ellos.

En Chile el desarrollo de la actividad minera dio lugar a diversos asentamientos de este tipo, que se repartieron a lo largo del territorio nacional y tuvieron manifestaciones hasta finales del siglo XX. Los asentamientos mineros del norte del pais cobran especial valor desde la segunda mitad del siglo XIX, toda vez que una parte fundamental del desarrollo económico nacional estuvo basado en la explotación de este tipo de recursos naturales. Los pueblos y campamentos mineros de Chañarcillo, Caracoles o las mismas salitreras pueden ser consideradas verdaderas comunidades cerradas y habitadas solo por aquellos que desempeñaban labores extractivas o por quienes prestaban servicios a su población y actividades (Bravo, 2000). Formas más claras de company-towns se encuentran en las ciudades del cobre, levantadas a lo largo del siglo XX, como Sewell (1906), Chuquicamata (1915), Potrerillos (1920), El Salvador (1959) y otros más recientes como San Lorenzo (1995) y Doña Inés de Collahuasi (1999), todos ellos en el norte del país e impulsadas por inversiones privadas (Garcés, 2004).

Aún más parecidos a los barrios cerrados contemporáneos fueron los callejones alineados de habitaciones precarias, denominados como conventillos en Chile, tugurios en Perú, cortiços en Brasil o ciudadelas en Cuba (Hidalgo, 2002a). En general, nacieron en las antiguas casas patio, abandonadas por la clase alta, que migró hacia la periferia de la ciudad y se instaló en lujosas residencias, siguiendo el modelo de la ciudad jardín.

En el caso chileno esta forma de habitar se asocia fundamentalmente a una vivienda colectiva y tuvo variados matices y diversos origenes. Por una parte, coinciden con lo expuesto, formándose por la acción deliberada de los antiguos propietarios de las casas patio ubicadas en las zonas centrales de las ciudades, que las subdividieron y comenzaron a alquilar las habitaciones en forma separada. Con un bajo nivel de inversión, los mismos dueños reacondicionan esas viviendas para obtener beneficios económicos. Por otra parte, esta tipología correspondió a construcciones precarias concebidas originalmente como "conventillos", para ser puestas en el mercado de alquiler (Hidalgo, 2002b).

El impulso dado a la construcción de viviendas obreras, llevará a diseñar unidades residenciales agrupadas y diseñadas con parámetros de rendimiento económico. Así nacieron los cortiços alineados en Brasil (Bonduki, 1999), los "cités" en Chile (Hidalgo, 2002b) y se potenciaron las vecindades en México (Ribera, 2003). En este primer país se ha postulado que ante la ausencia de una política habitacional estatal, la solución "liberal" al problema de la vivienda condujo a dos tipos de promociones, con distin- 
tos resultados en la morfología urbana: la construcción de "casas de renta", o "hileras" de viviendas "higiénicas" -cortiços alineados- destinadas al alquiler o venta para los sectores de clase media, generalmente en barrios cercanos a las áreas centrales; y la oferta y venta de lotes de tierra en la periferia, que llevó a la autoconstrucción de la vivienda por parte de las clases populares (Rodríguez Soares e Hidalgo, 2003).

En México estas viviendas colectivas tienen su origen en residencias construidas por la iglesia católica para ser arrendadas. Se ajustaron a un "modelo de casa centrado alrededor del patio con su corredor porticado, y sobre el que se abren las puertas de numerosas viviendas de uno o dos cuartos a lo sumo" (Ribera, 2003). La puerta defendió la vecindad contra el mundo exterior, contra la violencia de personas o del Estado. Cabe destacar que esta forma de edificar conjuntos de vivienda perduró en México prácticamente hasta la década del '70.

En Chile estos conjuntos de "casitas" fueron de edificación continua, alineadas en torno a un espacio común, privado, el que tiene relación con el acceso a la vía pública. La denominación de "cité" tiene como origen esta forma especial de relacionarse con el espacio público exterior, que recuerda la ciudadela medieval amurallada. El número de casas de cada conjunto fue variable, cuando fueron dirigidos a los estratos obreros fueron de mayor cantidad que los dirigidos a sectores medios; los de menor superficie en general, contaban con dos o tres habitaciones, baño, cocina y en ocasiones un pequeño patio. Estas agrupaciones de viviendas se incorporaron a la trama urbana sin alterarla, por el contrario, densifican el interior de las manzanas, originando un tipo de residencia que aún perdura.

\section{Los loteos suburbanos de elite como base de los barrios cerrados modernos del siglo $\mathrm{XX}$}

No solo los barrios cerrados de la clase baja o media tienen sus antecesores (en este caso: los conventillos, tugurios, cités, vecindades o contiços alineados), sino también los barrios amurallados de la clase alta. Muchos de estos se desarrollaron en base a los Clubes de Campo (country club), Club de Golf y Loteos Privados, que fueron cercados prácticamente desde la década de 1970.

La forma inicial de un Club de Campo es el Club Campestre de la Ciudad de México, conocido también como "Churubusco Golf Club". Su génesis corresponde al estereotipo de una forma de vida, exportada de otro espacio cultural para Latinoamérica. Hacia 1900 algunos ingleses encontraron la naturaleza plena, en un área conocida como "Los Pinos", cerca del perímetro de la Ciudad de México, para jugar golf. En 1905 ellos adquieren un terreno de 72 has, en el que instalaron un campo de golf de 18 hoyos y una "casa club" con sala de bailes, que pronto fue aceptada por la sociedad urbana para sus festividades. Así los fundadores obtuvieron ganancias que les permitieron construir sus propias casas, las que con el tiempo fue- 
ron representativas de dicho club, cercado descle su origen. Hoy día existen en el terreno del "Fraccionamiento Cerrado Club de Golf de Churubusco" 19 chalets, una casa de Club, un campo de golf de 18 y un otro de 9 hoyos, campos de tenis, un pabellón de gimnasia, una piscina y un parque con estanque (Borsdorf, 2003 b).

En el "Churubusco Club" el motor del fraccionamiento fue el deporte. En otros países los "countries" nacieron en los años 1950 y 1960, cuando, después de la Segunda Guerra Mundial el modo de vida de las clases altas latinoamericanas se movió hacia el llamado "sueño norteamericano", que tuvo al suburbio en uno de los emblemas sobre los cuales los agentes urbanos estadounidenses promovieron la venta de viviendas de baja densidad en la periferia de las ciudades, representando por largos años uno de los productos arquetipos a los cuales una familia de ese país debía acceder.

En Buenos Aires los emprendimientos exclusivos de este tipo aparecen hacia finales de la década de 1920. Ellos estuvieron relacionados a algunas actividades deportivas o de ocio, como el polo, la hípica o la navegación fluvial. Uno de los loteos pioneros lo constituye el Country Club Tortugas fundado en 1930 y ubicado a $38 \mathrm{Km}$. al noroeste de Buenos Aires, nace como un lugar destinado a la práctica del polo que se consolida posteriormente como un desarrollo residencial de elite (Thuillier, 2005, Clichevsky, 2002). Pensadas originalmente como residencias secundarias, en los primeros diez años sólo existían 25 construcciones y todos los propietarios tenían relaciones de amistad entre ellos y con el dueño del terreno (Fava, 2005).

El requisito para construir las viviendas era que su diseño debía basarse en tipologías cercanas al estilo español californiano, cuyo testimonio se puede encontrar en "las ornamentaciones con rejas, los miradores con techos de tejas romanas y las galerías que se pueden apreciar en las casas que se conservan de la primera época" (Fava, 2005). El equipamiento original de Tortugas contaba con club bouse, canchas de polo, tenis y pileta olímpica, y se emplazaba en pleno campo abierto. En los años iniciales de su desarroilo se comenzó la construcción de la primera etapa del campo de golf, actualmente de 18 hoyos.

La extensión del predio es de 280 hectáreas y cuenta con 430 lotes. Es uno de los clubes de campo más exclusivos y tradicionales, y tal vez el más consolidado en cuanto a infraestructura, servicios y viviendas, En la actualidad la cantidad de casas construidas es de 385 viviendas que van de los 180 a $\operatorname{los} 800 \mathrm{~m}^{2}$ (Vidal Koopmann, 2005). La ubicación del Tortugas es en el partido de Pilar, donde se han localizado en las últimas décadas los principales emprendimientos de barrios cerrados en el área metropolitana de Buenos Aires (Vidal Koopmann y Dietrich, 2005)

En Santiago, los loteos privados que fueron de uso exclusivo de sus residentes aparecen a fines de la década de 1940. Este es el caso del Parque Residencial 
Manquehue de Lo Curro, que como otras subdivisiones de suelo rustico realizadas en la periferia oriente de la ciudad de Santiago, se realizaron sobre la base de grandes predios, cuyos tamaños promediaban los $5.000 \mathrm{~m}^{2}$. En una superficie cercana a las 350 hectáreas, con 277 lotes, el proyecto de Lo Curro contempló: lagunáa artificial, country club, iglesia, colegio, parque y centro comercial (ver figura $\mathrm{n}^{\circ} 1$ ). Aunque muchos de estos equipamientos no se concretaron, subyace en ellos la idea de generar un núcleo auto-referente, que se veía reforzado por las características naturales del emplazamiento, la que se manifestaba en un vallado producto de la topografía del lugar.

Los propietarios de este fraccionamiento formaron una sociedad anónima que administró algunos servicios concesionados por la entonces municipalidad de Las Condes, entre los que se contaba la luz eléctrica y el agua potable. Dicha sociedad también debía "propender a hacer de ese lugar un Parque", situación que es reforzada en varios puntos de la ordenanza que en 1950 dio lugar al loteo. Estas propuestas ancladas en la tradición de la ciudad jardín, estuvieron en el centro de la citada ordenanza y plano del Parque Residencial Manquehue de Lo Curro, donde los propietarios debían como norma "forestar cada uno de sus lotes, con el objeto de hacer de la zona un lugar de arboladas", punto que es reforzado a través del sistema de setos vivos empleado en el cierre de los deslindes de las parcelas, los que debían afirmarse con "alambres de púas o con mallas de alambre, con una altura máxima 1,40 metros, prohibiéndose la construcción de panderetas o muros llenos" (Ministerio de Obras Públicas, D. S. n 808, 1950).

Sin embargo hay que considerar que los clubes de campo o loteos privados, por lo menos en sus principios, no fueron simples copias del modelo norteamericano. También respondieron a una época de rápida industrialización, basada en las políticas "keynesianas" adoptadas en la mayoría de los países de la región, cuestión que potenció una creciente motorización urbana que comenzó a ser símbolo de ruido y contaminación del ambiente. Ello llevó muchas veces a la búsqueda de aire puro y un estilo de vida campestre, situación que tiende a ser más acentuada en aquellos países donde es idealizada la forma de habitar del mundo rural, representada en el "gaucho" en Argentina, Uruguay y sur de Brasil o el "huaso" en Chile. La afición de la clase alta por la vida rural, como "elemento definitorio de la identidad del grupo" (Stabili, 2003), llevó a la elite, desde comienzos del siglo XX, a buscar su residencia en espacios semirurales, no consolidados y alejados de los problemas visibles de lá ciudad como pobreza, delincuencia, alcoholismo y hacinamiento tan comunes en las clases bajas de la pasada centuria.

Atrás de estos movimientos migratorios residenciales que realizan las elites existe un desencadenamiento particular del proceso de segregación socio espacial. La localización de sus residencias en territorios exclusivos, tanto en lo social como en lo pai- 
sajístico, son signos de distinción que se traducen en la construcción de áreas residenciales separadas del resto de la ciudad. Lás elites en este caso actúan como agentes de cambio e innovación en la ciudad y dirigen con su localización las tendencias de expansión de la ciudad (para Santiago ver Sabatini y Cáceres, 2001 y para Buenos Aires Torres, 2001).

A partir de lo anterior, podemos señalar que en el mismo grado que el rápido desarrollo de los barrios "country" en los años " 80 puede ser interpretado como resultado de la globalización y del neoliberalismo (Hoffmann, 2002), es posible también explicarlos como consecuencia de la idealización de la vida campestre en muchos países del subcontinente y como un modo de imitación por parte de las clase medias a lo realizado por la elite, en su constante esfuerzo por igualárseles.

\section{Los edificios racionalistas y los barrios cerrados en altura}

En el contexto del Estado Nacional Desarrollista asociado al mencionado modelo de desarrollo económico "keynesiano", se producen en la mayoría de los países latinoamericanos importantes transformaciones en su base económica. Bajo el para-

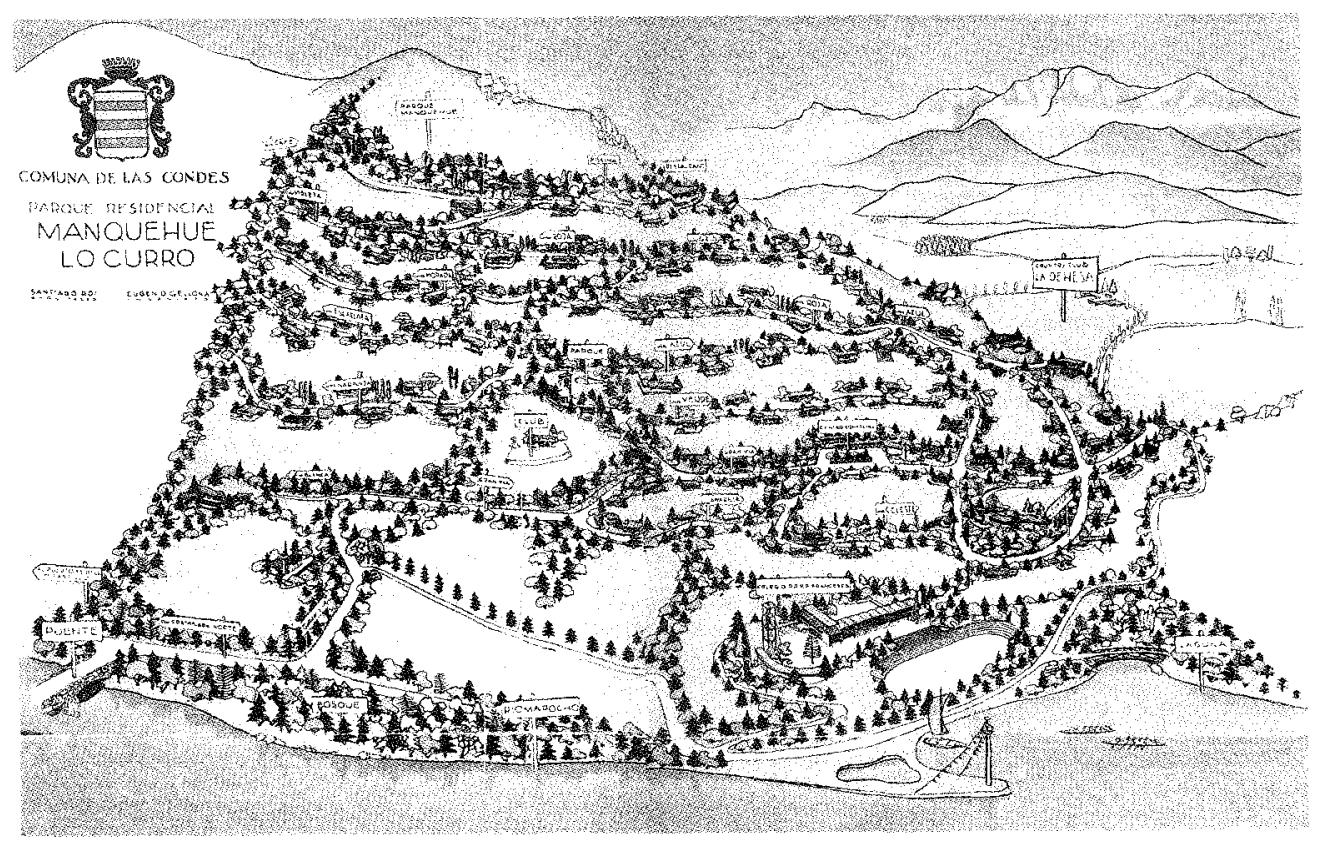

Figura 1. Proyecto Parque Residencial Manquehue de Lo Curro. Fuente: Larrain, 1952. 
digma de la substitución de importaciones, que cobra fuerza a contar de la cuarta y quinta década del siglo XX, el Estado actúa como promotor de la actividad industrial e interviene activamente en el diseño de las políticas sociales, entre las cuales la provisión de vivienda fue una de las principales. En esos años proceso de urbanización, entendido como el cambio de los patrones culturales desencadenado por la migración hacia las grandes urbes y el aumento de la población en las ciudades que transforma la ocupación del suelo urbano, toma su máxima expresión en este periodo (Hidalgo, 1999).

El Estado no sólo apoya la construcción de viviendas para los grupos más necesitados, sino que también facilita el acceso a la casa propia por parte de la clase media. Existe una necesidad de industrializar la producción de vivienda para con ello reducir los costos de producción por unidad edificada y ampliar así el número de beneficiarios de dichas políticas. Lo anterior dio lugar a la aparición del concepto de vivienda económica (Aynomino, 1976), que estuvo vinculado a los primeros Congresos Internacionales de Arquitectura Moderna. Ellos propiciaron decididamente la edificación en altura, lo que se expresó en la construcción de bloques de vivienda en altura que pretendieron, en palabras de Le Corbusier (1976), racionalizar el uso del espacio urbano.

En Chile la Caja del Seguro Obrero y algunos particulares que participan del negocio inmobiliario a edifican, comienzos de la década de 1930 , los primeros conjuntos de viviendas verticales conocidos como edificios de departamento (Hidalgo, 2005), otro tanto ocurre en Brasil, en similar período, con los conjuntos levantados por los Institutos Aposentadoria e Pensōes (Bonduki, 1999), por su parte en México, en la década siguiente, aparecen los conjuntos que impulsa el Banco Hipotecario Nacional (Villavicencio y Durán, 2003).

En Santiago los agentes privados vieron en la construcción de bloques de vivienda en altura un negocio que comenzaba a reportar ganancias, y aprovecharon, de paso, el impulso del sector público dado a la construcción de viviendas mediante dos mecanismos: (1) construcción de las viviendas de promoción pública para la clase media y (2) edificación de unidades para ser colocadas en el mercado de lá vivienda nueva, beneficiándose de todas las ventajas tributarias que ofrecía el Estado para el desarrollo del negocio inmobiliario (Hidalgo, 2005). Además, los particulares localizaron sus proyectos en aquellos lugares cercanos al casco histórico de la ciudad y aprovecharon con ello las ventajas de localización que la centralidad otorga en términos de equipamientos y servicios.

Precisamente este último aspecto fue unos de los fundamentos utilizados para aprobar en 1937 la primera normativa chilena que aborda la propiedad común en el 
siglo XX, denominada Ley de Venta por Pisos y que impulsó tempranamente la edificación de los condominios verticales. Estos barrios cerrados derivados de la aplicación de dicha normativa fueron vistos en aquellos años como intervenciones que ayudarían a dinamizar el mercado del suelo de las áreas centrales, señalándose que en "terrenos de gran valor, ubicados en barrios centrales, y tan pobremente edificados que escasamente producen renta a sus dueños, pueden aprovecharse en extensos blocks de construcciones de la arquitectura moderna, sin que ello signifique grandes y permanentes desembolsos, pues tan pronto está terminado el edificio ya se pueden vender sus diversas secciones, como se vende un fundo por hijuelas" (Tagle, 1937).

Los condominios verticales amparados en la ley copropiedad se difundieron en la mayoría de las ciudades chilenas y dieron lugar a una forma urbana que se introduce en la ciudad a través de la densificación de la trama preexistente. Ellos representan una modalidad de fragmentación del espacio interior de la ciudad a través de la generación de pequeños $\mathrm{y}$, a veces, medianos fraccionamientos, que imponen un sistema de acceso controlado a los predios y fincas que los componen, los que en definitiva son barreras físicas que separan a sus moradores del mundo exterior.

La dinámica y el significativo crecimiento del sector inmobiliario vinculado a las agrupaciones residenciales en condominio, en la década de los ochenta y comienzo de los años noventa, hicieron necesario que se modificara el cuerpo legal de 1937, dando paso en 1997 a la Ley de Copropiedad Inmobiliaria. Concretamente uno de los argumentos esgrimidos para el mencionado cambio fue el de flexibilizar la administración de los condominios, especialmente hacer más viable la gestión de aquellos conjuntos de gran tamaño y, en general, robustecer también el principio de que son los mismos propietarios quienes mediante la expresión de su voluntad decidan sobre la vida del conjunto residencial, sus modificaciones y situaciones por el estilo (Figueroa, 2000).

Los cambios en la legislación aludidos expresan que en la década de 1990 se produjeron modificaciones en la construcción de condominios en Chile, situación que mostró su correlato en la morfología de las ciudades y en especial en las áreas metropolitanas. El aumento del tamaño de las intervenciones y del número de viviendas involucradas en ellas, es precisamente uno de los aspectos más relevantes que llevaron a la renovación de la citada normativa. Este punto representa también una nueva manifestación de la forma en que el espacio urbano comienza paulatinamente a cerrarse a través de conjuntos de vivienda cada vez mayores, construidos con tipologías diversas que están marcadamente segmentadas según el estrato social y, a su vez, localizados en diferentes puntos de la ciudad. 


\section{Los barrios cerrados y formas recientes de fragmentación en el área metro- politana de Santiago}

Los cambios anteriormente señalados pueden enmarcarse dentro de la influencia provocada por la transformación económica reciente, que tiende a producir formas similares de asentamiento de la población, situación que permite leer el crecimiento de algunos barrios cerrados, que no son copias modernas de las vecindades o las "cités" y no se entienden como "country" o "loteos privados" (Borsdorf e Hidalgo, 2004). En esta dimensión, se debe tener en consideración que los procesos de mutación territorial de la globalización, refuerzan y amplifican la construcción de cierto tipo de barrios cerrados. Capaces de modificar el conjunto de la estructura urbana (figura $n^{\circ} 2$ y $n^{\circ} 3$ ), los emprendimientos residenciales amurallados de los noventa tienden a aumentar la superficie y el número de viviendas, además de contar con la participación de capitales externos a los países donde se materializan, junto con una exacerbación de las medidas de seguridad y una amplia variedad de equipamientos de uso común en su diseño.

Esta situación sumada al importante valor que las capas altas de la sociedad latinoamericana le otorgan a la esfera de la vida privada y su permanente afán de distinción del resto de la sociedad, explica en parte la vigorosa difusión mostrada por los barrios cerrados en las últimas décadas. Ello también se ve complementado por el constante seguimiento o imitación que los grupos que se sitúan en una escala inferior a las élites hacen de ellas, llevando muchas veces a vivir en un barrio cerrado a las clases media por un asunto de "moda", en la que también participan las inmobiliarias que ofrecen un producto de consumo que prácticamente no tiene alternativa en el mercado de la vivienda nueva, explotando la venta de seguridad asociada a este tipo de emprendimientos.

Como queda demostrado en los puntos anteriores, el cierre del espacio residencial en las ciudades iberoamericanas no es un fenómeno reciente (figura $n^{\circ} 4$ ), sin embargo experimenta, desde los años ochenta, un importante aumento. Santiago es buen ejemplo para aproximarse a esta situación, debido a que, en los distintos municipios que conforman su espacio urbano, se consolidan en este período las más diversas modalidades de barrios cerrados.

La situación chilena es además un verdadero paradigma de la forma en que se llevaron a cabo las reformas neoliberales, iniciadas a mediados del decenio de 1970, las que tuvieron en el sector inmobiliario a uno de los motores que debía liderar la nueva economía. Para poner en marcha este postulado, una de las primeras medidas que se impulsan en aquellos años es la desregulación del mercado del suelo, que se constituye en un puntal del desarrollo urbano. Esto se traduce en una progresiva flexibilidad de los instrumentos de planificación territorial -planes de uso del suelo-, que 
cada vez ven más reducido su campo de acción a favor de las grandes inversiones que son necesarias para los "adelantos de la ciudad".

Al igual como ya se delineó en los puntos anteriores, la hipótesis expuesta debe ser asumida con cautela, lo que necesariamente conduce a adentrarse con cierta detención en la última fase de la construcción de las áreas habitacionales enclaustradas en la capital chilena, con el fin de formular un marco explicativo de dicho proceso. En este contexto, se debe tener en cuenta que así como existen precedentes de barrios exclusivos y de acceso limitado a sus residentes, ellos fueron una porción reducida de un mundo urbano que en general se edificó con un trazado vial que permitía la libre circulación.

Sin embargo, la situación actual es bastante diferente, y la construcción de nuevas viviendas por lo general se hace en base a un diseño de perímetros cermados y acceso controlado. El paradigma de la globalización calza, en gran medida, en el escenario descrito, no obstante existen manifestaciones locales del proceso que son necesarias de analizar, como la amplia gama de tipologías con diversas localizaciones, habitadas por diferentes clases sociales, que la realidad chilena ofrece.

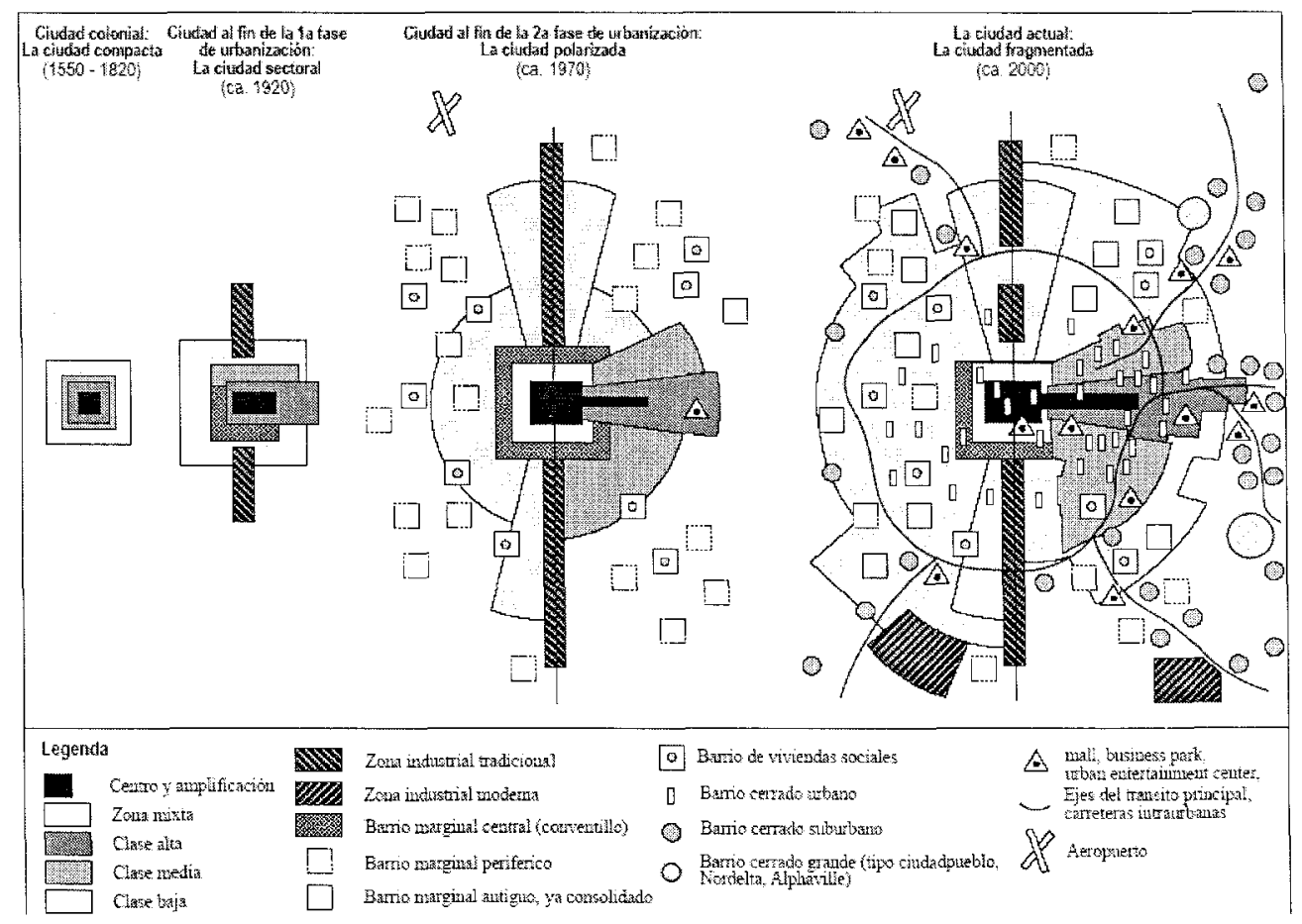

Figura 2. Evolución del modelo de estructura urbana de la ciudad latinoamericana. 
Los barrios cerrados en este país, conocidos comúnmente como condominios, muestran distintas tipologías que van desde un grupo reducido de viviendas, pequeños condominios, entre cinco y veinte unidades de casas unifamiliares o edificios de 6 y 20 departamentos aproximadamente, hasta proyectos que superan el centenar de viviendas, principalmente de residencias unifamiliares, que hemos denominado urbanizaciones cerradas. A continuación y a modo de contribuir a la diferenciación de la situación chilena con el resto de los países latinoamericanos se propone la siguiente clasificación de barrios cerrados existentes en los diferentes municipios de la ciudad de Santiago y que han sido diseñados por los promotores inmobiliarios como tales"

Viviendas unifamiliares en copropiedad: poseen perímetro cerrado, acceso controlado y vigilancia permanente o semipermanente. Los de menor tamaño se han construido muchas veces al interior del área urbana y los de mayor se ubican en la periferia de la ciudad. En general se aplica en ellos la Ley 19.537 de Copropiedad Inmobiliaria de 1997.

Urbanizaciones cerradas: Corresponden a conjuntos de viviendas unifamiliares de más de 100 viviendas, con perímetro cerrado y accesos controlados. En la mayoría de las ocasiones no se encuentran amparados en la normativa de copropiedad y han logrado legalidad a partir de la aplicación de las ordenanzas locales de cierre de calles y pasajes.

Edificio(s) de departamentos: Acceso controlado, vigilancia permanente o semipermanente y sistema de administración. Se acogen a la Ley de Copropiedad y se han construido en distintas zonas de la ciudad desde el centro a la periferia.

Loteo de Parcelas de Agrado: Unión de predios desde $5.000 \mathrm{~m}^{2}$ en espacios periurbanos, acceso controlado y edificación libre en base a normativa interna del condominio.

Estas variantes informan de la evolución reciente de los espacios residenciales cerrados en Santiago. Como apuntamos, la forma primaria de condominio se da en el contexto santiaguino a raíz de la Ley de Venta por pisos de 1937, que amparó las edificaciones en altura y fue la primera en normar el régimen de copropiedad inmobiliaria. Ella corresponde al punto de partida jurídico que tuvieron los promotores de construir viviendas en altura, las que representan, a su vez, la imagen del condominio chileno hasta mediados de la década de 1970.

\footnotetext{
5 Existen también otras clases de barrios cerrados, como son los "condominios de facto", clonde los vecinos, con o sin permiso municipal, cierran los accesos de las calles y los "condominios de viviendas sociales" de edificios de departamento, que tienen el estatuto jurídico, pero que difícilmente se constituyen formalmente como tales.
} 


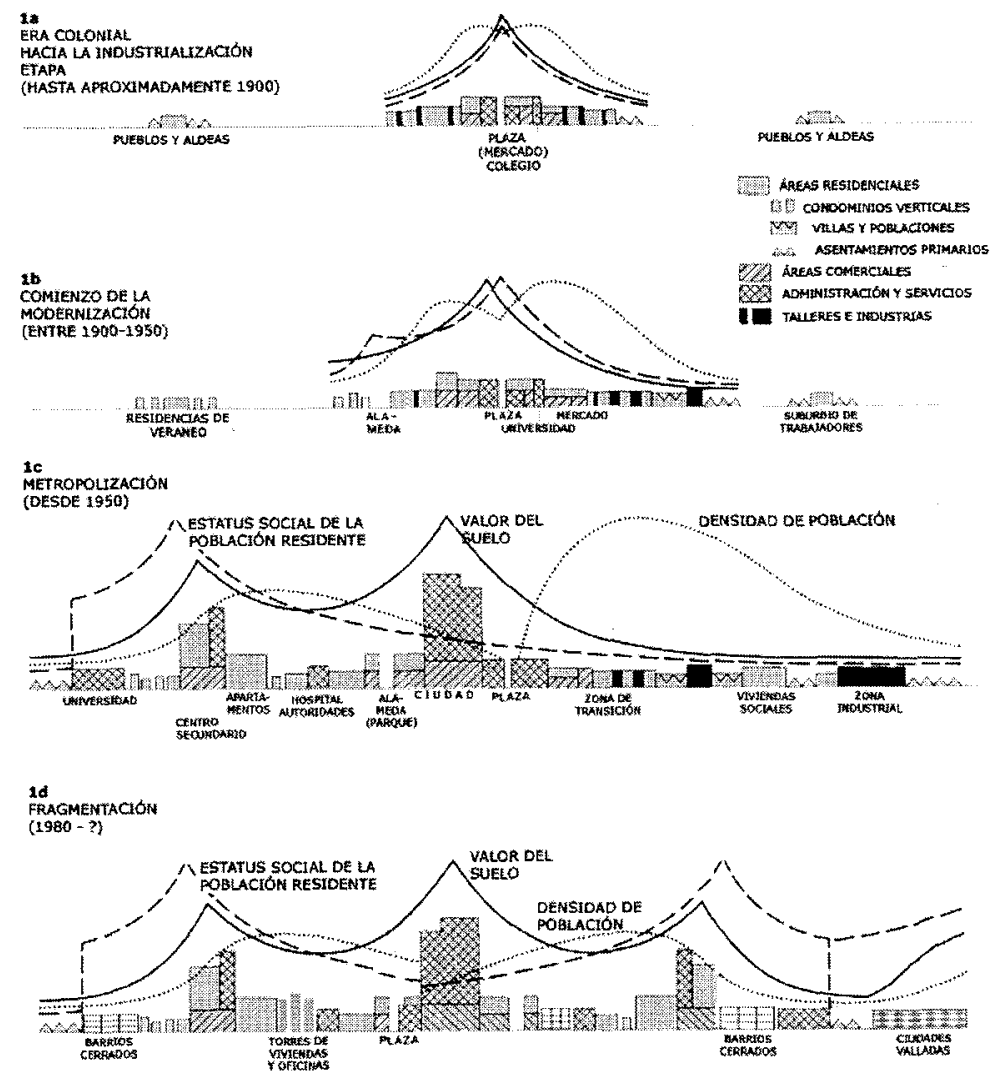

Figura 3. Evolución de los principales elementos de la organización urbana en la ciudad latinoamericana (modificado de Gormsen, 1981).

Es en este último período cuando comienza a irrumpir en Santiago las llamadas comunidades de Fernando Castillo Vèlasco. Fue en la comuna de La Reina, al oriente de la ciudad, en que dicho arquitecto diseña en base a una subdivisión del suelo preexistente, que oscilaba entre 0,5 a 4 hectáreas, grupos de casas unifamiliares con acceso común, orientadas a estratos profesionales. Castillo Velasco actuó como diseñador y promotor de sus intervenciones, tareas que involucraron la organización previa de los usuarios a la compra de los terrenos con ellos, pasando por la búsqueda de financiamiento hasta el diseño de los proyectos y la supervisión de la construcción (Browne, 1990).

Bajo el principio de organizar comunidades, compuestas en general por familias de intelectuales y artistas, que compartían sus puntos de vista, Castillo Velasco 
irrumpe en la ciudad con una nueva forma de organizar las áreas residenciales, explotando exclusividad, diseño y paisaje (Eliash, 1990). El hecho de que los habitantes de estas comunidades poseyeran tendencias políticas y culturales comunes, ha llevado a catalogarlas como "condominios ideológicos" (Borsdorf, 2000). Hacia comienzos de la década de 1990 se contabilizaban en estos conjuntos residenciales "unas 360 viviendas y más de 2000 habitantes" (Browne, 1990).

Con variaciones a la propuesta original de Castillo Velasco, la década de los ochenta verá ampliación de esta pauta de edificación, difundiéndose de paso a otros municipios de Santiago. Lo anterior permite señalar que el punto de partida del aumento del enclaustramiento habitacional santiaguino es el pequeño condominio, que no supera una treintena de unidades. Esta forma de construir viviendas está asociada a un acomodo del diseño arquitectónico a la morfología urbana ya consolidada. Se obtienen, de esta forma, mayores rendimientos del suelo, similar, pero en una escala menor, a lo que ocurre con la edificación en altura.

Los proyectos más pequeños de este tipo pueden compararse a los ya referidos cités construidos en las postrimerías del siglo XIX e inicios del siglo XX. Aunque las superficies de las viviendas de los condominios edificados en los años ochenta y noventa es mayor, existe en ellos cierta reminiscencia de introducir en el espacio urbano un modo de edificación que aprovecha la parcelación del suelo yá existente.

En el ocaso del último decenio del siglo XX, los barrios cerrados comienzan a aumentar paulatinamente su tamaño, superando un gran número las 100 unidades y de paso son trasladados por los promotores a comunas de menores ingresos. Aquí los barrios amurallados conducen a lugares más desfavorecidos a población de más alto nivel socio profesional. Esta situación constituye la base del proceso de fragmentación socio espacial del área metropolitana de Santiago y es homologable a los sucedido en otras ciudades latinoamericanas, como lo que ocurre el área metropolitana de Buenos Aires, en el municipio del Pilar, habitado por población de escasos recursos y en el que se han localizado los proyectos de barrios cerrados de mayor magnitud en los últimos años (Vidal Koopmann, 2003, Vidal Koopmann y Dietrich2005). Esta situación ha llevado a algunos investigadores a plantear cómo el mosaico social de la ciudad comienza a transformarse y mostrar formas de agrupamiento que rompen de alguna forma la tendencia de acumular en determinadas áreas a estratos socioeconómicos similares. En este sentido, se señala que "la construcción de condominios cerrados para grupos medios y altos fuera de su área tradicional de concentración, es tal vez el cambio más notorio y generalizado que está afectando a lá estructura interna de las ciudades chilenas y latinoamericanas" (Sabatini, Cáceres y Cerda, 2001).

A su vez en los primeros años del siglo XXI nace un fenómeno que anclado en el proceso descrito marca un punto de inflexión en el diseño de los barrios cerrados en 
Santiago y tiene que ver con los megaproyectos residenciales, cuya población proyectada supera los 50.000 habitantes. Constituyen un nuevo concepto de ciudad rodeada de muros, vallas, portones y sistemas cle seguriclad para proteger a sus miembros de manera hermética y excluirlos del mundo exterior. Son, además, comuniclades provistas de prestaciones de servicios y abastecimiento propias -en otras palabras, autosuficientes-, pero reservadas únicamente a un cierto estrato social. En determinadas ocasiones -como en el caso de Santiago de Chile- esos megaproyectos se conectan a los cascos urbanos a través de autopistas privadas transitables muchas veces sólo por quienes moran en esos nuevos complejos residenciales (Borsdorf e Hidalgo, 2005).

Esta situación se produjo con anterioridad en Argentina y Brasil, donde proyectos como Nordelta en Buenos Aires y Alphaville en Sao Paulo son todo un símbolo de verdaderas ciudades fortificadas, que están transformando notablemente los modos de habitar urbano en dichos países. Por ejemplo, Nordelta "se urbaniza desde 1999 en un área de 1.600 hectáreas y se construye una infraestructura habitacional para 80.000 personas de altos ingresos, separadas del resto de la sociedad urbana por fuertes medidas de seguridad; además, se encuentran en construcción todos los servicios comunes de una ciudad, como instalaciones culturales, de esparcimiento, de compras y un centro de oficinas" (Janoshka, 2002). En el caso de Alphaville, edificado en etapas desde mediados de los años ' 70 por una empresa del mismo nombre, que lleva adelante proyectos en diversas ciudades del Brasil, corresponde a una verdadera ciudad habitada por cerca de 30.000 personas, que cuenta con una amplia gama de servicios en su interior (Coy y Pöhler, 2002).

En este nuevo dibujo de la geografía del espacio residencial, existen otros hitos que comienzan a acompañar su conformación, como son el surgimiento de las nuevas centralidades (Escolano y Ortiz, 2005), asociadas a la difusión de los grandes centros comerciales, conocidos en Chile con el anglicismo mall. Junto con dichos elementos aparecen en los primeros años de este siglo, otros dispositivos que marcarán el desarrollo de la ciudad y sus tendencias de expansión, como es el sistema de vías concesionadas de alta velocidad, promovido por el Estado.

Ello refuerza las estrategias del sector empresarial inmobiliario, que comienza a desarrollar con decisión la edificación de condominios y paulatinamente va agrandando el volumen de las operaciones, tanto de viviendas unifamiliares como también de uno o más bloques de departamentos. Estas viviendas forjan auténticas urbanizaciones autosuficientes, en donde las firmas constructoras, brindan no solo la vivienda como producto de venta, sino que además una serie de equipamientos y servicios, que incluyen vigilancia permanente y áreas de recreación en su interior.

Concomitante con la situación ya descrita, en las comunas externas al límite de la mancha urbana continua de la aglomeración santiaguina, la construcción de espacios residenciales se intensifica en la década de 1990. En estas superficies se construyen 
viviendas unifamiliares en predios cuya superficie es igual o superior a media hectárea, que corresponden a la medida mínima de subdivisión de predios rústicos que establece el Decreto Ley 3.516 de 1980 , en paños cuyo promedio es de $5.000 \mathrm{~m}^{2}$. En los municipios con mayor proporción de suelo rural se llevaron a cabo importantes procesos especulativos en torno a la citada subdivisión, que se expresan en un bajo porcentaje de edificación de unidades residenciales en cada uno de los lotes subdivididos. A pesar de esta situación igualmente ello generó asentamientos dispersos que no están asociados a actividades agropecuarias, sino que manifiestan una extensión del modo de vida de la gran ciudad.

\section{Consideraciones finales}

En todas las ciudades las formas de habitar representadas en el diseño y disposición de las viviendas, dan cuenta de una distinción entre el ámbito privado y el espacio público. Sin embargo, en América Latina la difusión y aumento de los barrios cerrados desemboca en un retroceso de aquellos lugares de uso común de todos los ciudadanos, con lo que la movilidad y utilización de los diferentes territorios de la ciudad se ven limitados.

A su vez una de las características más resaltantes del desarrollo urbano en América Latina, reside en la fragmentación de la ciudad en numerosas unidades pequeñas especializadas, de acuerdo con sus funciones. La antigua bipolaridad con su correspondiente división de una ciudad para "ricos" y una para "pobres" vigente hasta la década de los setenta, ha sido superada. Islas para adinerados - como los barrios cerrados- se extienden por doquier en el área urbana. Templos de consumo, como los grandes centros comerciales y tiendas por departamento, ya no son, como antaño, un privilegio del barrio alto; sino que, están diseminadas por toda la ciudad. Lo que es aplicable al mercado habitacional y al comercio al por menor, se refleja también en los nuevos patrones de emplazamiento para las prestaciones de servicio y complejos industriales: las torres de oficinas no se construyen solamente en los barrios tradicionales de la gente acomodada, el casco antiguo de la ciudad y sus distritos aledaños, todavía en decadencia durante los años ochenta, vuelven a recibir fuertes impulsos de crecimiento vertical. El sector industrial tiende, finalmente, a agruparse cada vez más, en pequeños y medianos parques empresariales y a distanciarse de los emplazamientos tradicionales, que se relacionaban con las principales rutas de acceso de las grandes ciudades y vías ferroviarias.

Los barrios cerrados que nacieron en las últimas décadas tienen raíces en la tradición cultural latinoamericana. Sin embargo, la influencia de la globalización y la transformación económica y sus consecuencias, retraso del estado, desregulación del desarrollo urbano y de las normas de planificación, crecimiento de la criminalidad, son fuerzas poderosas que acrecientan el proceso. 
Respecto de esta última característica, la última década del siglo XX mostró un aumento del tamaño de los barrios cerrados en Santiago, representado por los conjuntos de más de 100 viviendas y que en la actualidad superan las 1000 unidades. Son precisamente este tipo de intervenciones la que comienzan a provocar cambios de gran escala en la conformación de la geografía social de la ciudad de Santiago y de sus formas de expansión. Ello es la expresión chilena de los grandes proyectos que se estaban ya generando en Argentina y Brasil, donde Nordelta en Buenos Aires y Alphaville en Sao Paulo son todo un símbolo de verdaderas ciudades fortificadas que están transformando notablemente los modos de habitar urbano en dichos países. Lo anterior expresa la proximidad que existen en los diseños de dichas intervenciones, y de la nueva forma en que se construyen los espacios urbanos de las ciudades América Latina.

La situación de Santiago a su vez informa que su morfología urbana se ha visto notablemente modificada por la edificación de barrios cerrados, la que fue capaz en la última década de conformar un nuevo dibujo de la estructura territorial metropolitana, marcado por la fragmentación y por el ingreso de este tipo de viviendas a lugares con la más diversa base social, situación que también es posible de ser observada, con diferentes expresiones, en el resto de las ciudades de América Latina. 
Plano

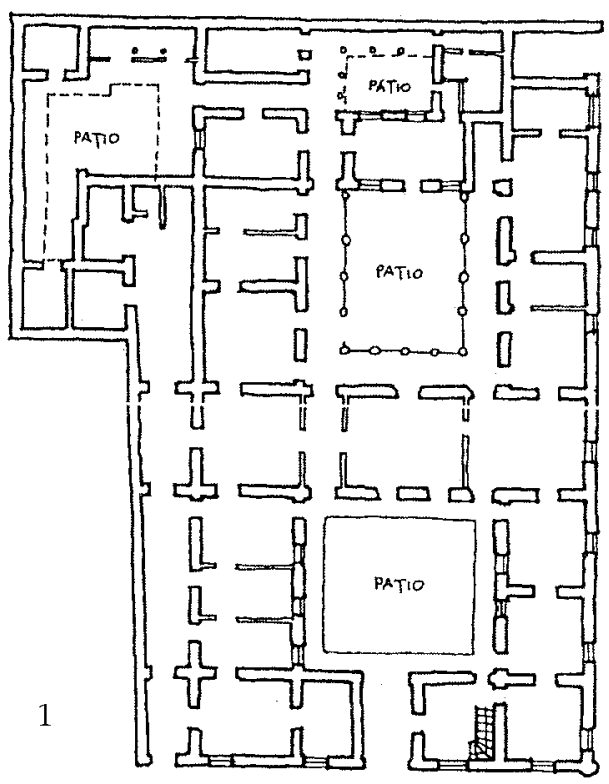

Fotografía

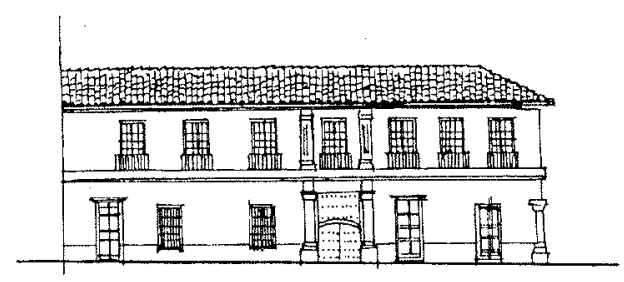

2
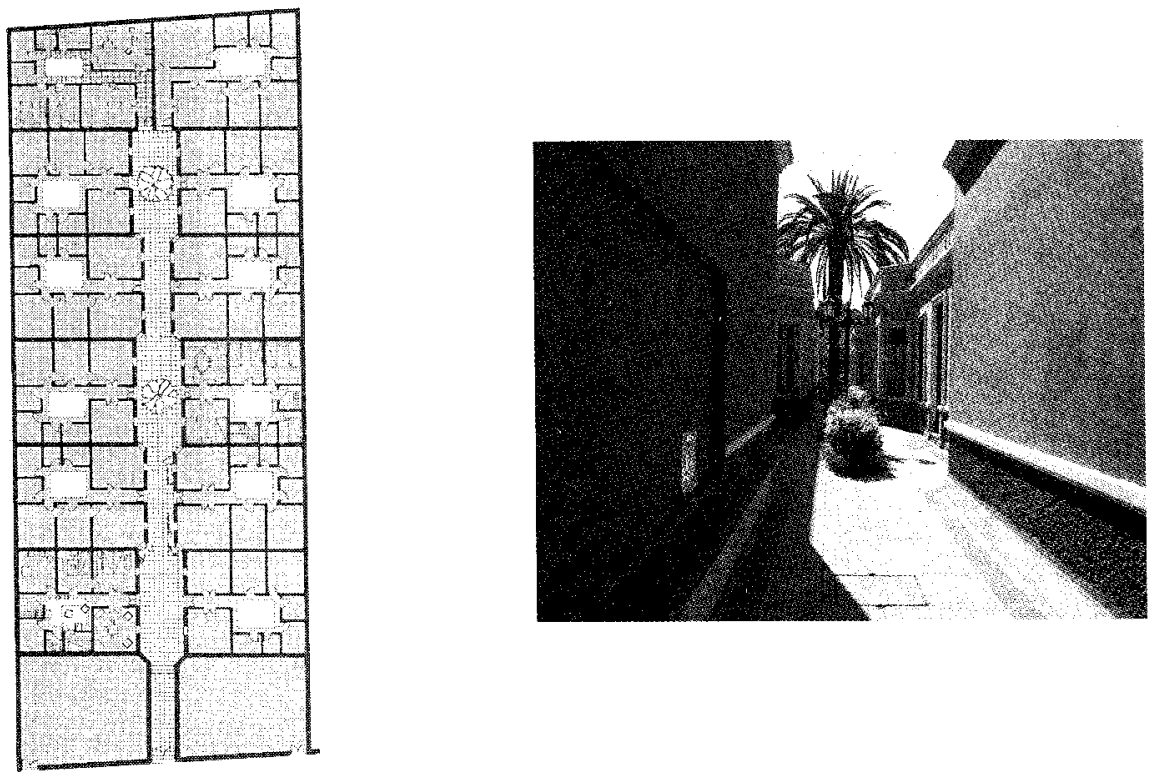

Figura 4. Evolución de algunas de las tipologias de barrios cerrados en Santiago de Chile: desde la casa patio a la urbanización cerrada. 

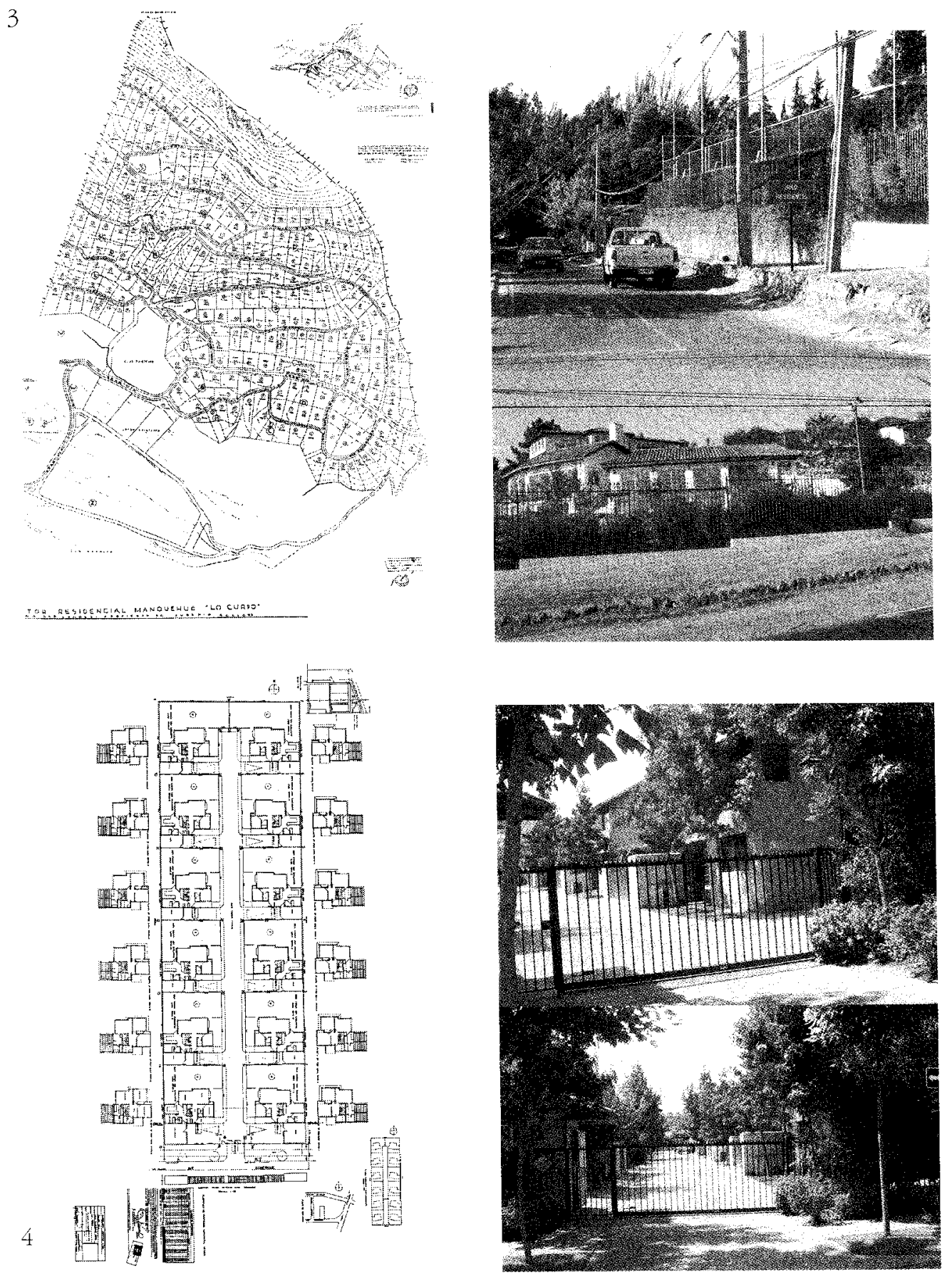

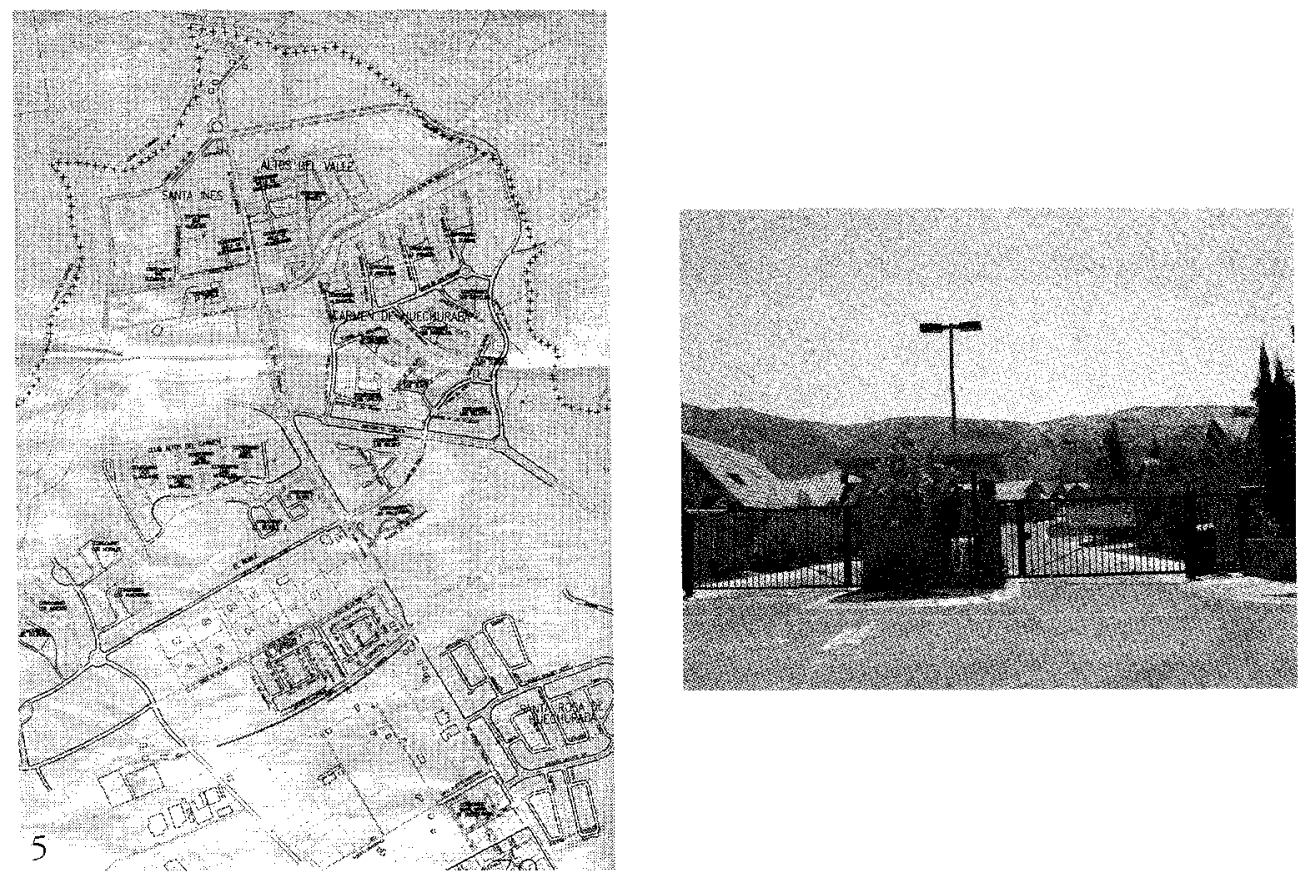

Leyenda

1. Plano y esquema casa patio (Sahadi, 1996).

2. Plano (Ortega, 1985) y fotografía (2005) cite en calle García Reyes, municipio de Santiago, construido en 1910.

3. Plano (Ministerio de Obras Pública, 1950) y fotografía (2005) Parque Residencial Manquehue de Lo Curro.

4. Plano y fotografía (2005) condominio cite en calle Echenique, comuna de La Reina, construido en 1993.

5. Plano de condominios que dan lugar a urbanizaciones cerradas en calle Avenida Pedro Fontova, municipio de Huechuraba en construcción desde la segunda mitad de la década de 1990. La fotografía (2004) muestra grupo de casas en la zona de El Carmen de Huechuraba. 


\section{Bibliografía}

Aymonimo, Carlos. La vivienda racional. Ponencias de los Congresos CIAM 19291930. Barcelona: Gustavo Gili, 1976.

Bonduki, N. Rigens da babitação social no Brasil. São Paulo: Estação Libertade, 2000.

Borsdorf, A. Die Condominios von Santiago de Chile als Beispiele sozialräumlicher Segregationstendenzen von Ober- und Mittelschicht in lateinamerikanischen Städten. In: Peripherie. Zeitschrift für Politik und Ökonomie in der Dritten Welt, 2000, n०80, p. 25-40.

Borsdorf, A. Barrios cerrados en Santiago de Chile, Quito y Lima: tendencias de la segregación socio-espacial en capitales andinas, En CABRALES, L.F. (Editor). Latinoamérica: países abiertos, ciudades cerradas. Guadalajara: UNESCO, 2002, p. 581-610.

Borsdorf, A. (a) Cómo modelar el desarrollo y la dinámica de la ciudad latinoamericana. EURE, 2003, n 86, p. 37-49.

Borsdorf, A. (b) Hacia la ciudad fragmentada. Tempranas estructuras segregadas en la ciudad latinoamericana. Scripta Nova. Revista electrónica de geografia y ciencias sociales. Barcelona: Universidad de Barcelona, 1 de agosto de 2003, vol. VII, núm. 146(122). <http://www.ub.es/geo$\mathrm{crit} / \mathrm{sn} / \mathrm{sn}-146(122)$,htm>.

Borsdorf, A. \& Ch. Stadel (eds.) Peru im Profil. Innsbruck: Inngeo 10, 2001.

Borsdorf, A. e Hidalgo, R. Formas tempranas de exclusión residencial y el modelo de la ciudad cerrada en América Latina. El caso de Santiago. Revista de Geografia Norte Grande, 2004, no 32, p. 21-37.

Borsdorf, A. e Hidalgo, R. Los Mega-diseños residenciales vallados en las periferias de las metrópolis latinoamericanas y el advenimiento de un nuevo concepto de ciu- dad. Alcances en base al caso de Santiago de Chile. Scripta Nova. Revista electrónica de geografia y ciencias sociales Barcelona: Universidad de Barcelona, 1 de agosto de 2005, vol. IX, núm. 194 (9). <http://www.ub.es/geocrit/sn/sn-1949.htm> [ISSN: 1138-9788].

Bravo C. La Flor del Desierto. El Mineral de Caracoles y su impacto en la economía chilena. Santiago: Ediciones Dibam-Lom, 2000

Browne, E. La arquitectura comunitaria de Fernando Castillo. En ELIASH, H. Fernando Castillo. De lo modemo a lo real. Bogotá: Escala, 1990, p. 193-199.

Clichevsky, N. Urbanizaciones exclusivas en Buenos Aires. Ciudad y Territorio. Estudios Territoriales, 2002, Vol. XXXIV, $N^{\circ} .133-134$, p. 503-527.

Coy, M \& Pöhler, M. Gated communities in Latin American megacities: case studies in Brazil and Argentina. Environment and Planning B: Planning and Design, 2002, volume 29 , p. 355-370.

Eliash, H. Fernando Castillo. De lo moderno a lo real. Bogotá: Escala, 1990.

Escolano, S, y Ortíz, J. La formación de un modelo policéntrico de la actividad comercial en el Gran Santiago (Chile) Revista de Geografía Norte Grande, 2005 , $n^{\circ} 34$, p. 53-64.

Fava, L. Historia: los primeros countries. Un sueño de visionarios. El Clarin, Buenos Aires, 28 de agosto de 2005 (http:/ www.clarin.com/suplementos/cou ntries/2005/08/27/y-00211.htm).

Figueroa, P. Génesis, aplicación, vigencia, características y régimen de bienes comunes. In UNIVERSIDAD CENTRAL DE CHILE. Seminario: Copropiedad Inmobiliaria. Santiago: Editorial Jurídica Conosur Ltda., 2000.1. 
Garcés, E. Las ciudades del cobre: Del campamento de montaña al hotel minero como variaciones de la company town. EURE (Santiago), dic. 2003, vol. 29, n 88, p. 131-148.

González, L. La casa de España en México. En DIEGO, R. Herencia española en la cultura material de las regiones de México. Zamora: El Colegio de Michoacán, 1993. p. 33-46.

Harvey, D. David Harvey. The condition of postmodernity: an enquiry into the origins of cultural change. Cambridge: Blackwell, 1990 (traducción al castellano La condición de la postmodernidad. Investigación sobre el origen del cambio cultural. Buenos Aires: Amorrortu, 1998).

Hidalgo, R. Continuidad y cambio en un siglo de vivienda social en Chile (1892-1998). Reflexiones a partir del caso de la ciudad de Santiago. Revista de Geografia Norte Grande, 1999, n०26, p. 69-77.

Hidalgo, R. (a) Higienismo, beneficencia católica y vivienda obrera en Chile a finales del siglo XIX. Estudos Ibero-Americanos, Porto Alegre: PUCRS, 2002, vol. XXVIII, n ${ }^{\circ}$ 1, p. 65-83.

Hidalgo, R. (b) Patrimonio urbano y vivienda social en Santiago de Chile. El legado de la Ley de Habitaciones Obreras de 1906. Revista Geográfica de Cbile Terra Australis, 2002, no 47, p. 7-16.

Hidalgo, R. La vivienda social en Chile y la construcción del espacio urbano en el Santiago del siglo XX. Santiago: DIBAM, 2005.

Hidalgo, R y Borsclorf, A. Barrios cerrados y fragmentación urbana en América Latina: estudio de las transformaciones socioespaciales en Santiago de Chile (19902000). En HIDALGO, R, TRUMPER, R. y BORSDORF, A. Transformaciones wbanas y procesos territoriales. Lechras del nuevo dibujo de la ciudad latinoameri- cana. Santiago: Serie GEOLibro, 2005, p. 105-121.

Hoffmann, ST. The clash of globalization. Foreign Affairs, 2002, vol. 81, n' 4 , p. $104-$ 115.

Janoschka, M. El nuevo modelo de la ciudad latinoamericana: fragmentación y privatización. EURE, 2002, n 85, p.11-29

Janoschka, M. u. A. Borsdorf. Condominios fechados and barrios privados: The rise of private residential neighbourhoods in Latin America. In: Glasze, G., C. Webstet u. K. Frantz (Hrsg.): Private Cities: Global and Local Perspectives. Studies in Human Geography. London, 2005.

Larraín, C. Las Condes. Santiago: Editorial Nacimiento, 1952.

Le Corbusier. La parcelación del suelo en las ciudades. In Aymonimo, Carlos. La vivienda racional. Ponencias de los Congresos CIAM 1929-1930. Barcelona: Gustavo Gili, 1976, p. 233-243.

Leon Echaiz, R. Historia de Santiago. Tomo I. La Colonia. Santiago: Municipalidad de Santiago, 1975.

López, L. (Coord.). Casas, viviendas y bogares en la bistoria de México. México: El Colegio de México, Centro de Estudios Históricos, 2001.

Marcuse, P. \& Kempen, R. (eds.). Globalizing Cities: A New Spatial Order: London and Cambridge: Blackwell Publishers, 2000.

Meyer, K. \& Bähr, J. Lá clifusión de condoninios en las metrópolis latinommericanas. El ejemplo de Santiago de Chile. Revista de Geografia Norte Grande, 2004, no 32, p. 3) -53 .

Ministerio de Agricultura. Decreto Ley' 3516, establece subdivision de Predios Rústicos. Santiago: Ministerio de Agricultura, 1980.

Ministerio de Obras públicas y víls de Comunicación. Decreto Supremo no 808 , 
27 de abril de 1950. Diario Oficial de la Repuiblica de Chile, 1950, $\mathrm{n}^{\circ}$ 21701, p. 1123-1124.

Ortega, Oscar. El cité en el origen cle la vivienda chilena. CA, Revista Oficial del Colegio de Arquitectos de Chile, 1985, no 41, p. 18-21.

Ramírez, E. Concepciones del espacio urbano. En Diego, R. Herencia española en la cultura material de las regiones de México. Zamora: El Colegio de MichoaCán, 1993, p. 83-94.

Revista CA. El Modelo de la casa de 3 patios, Revista CA, Colegio de Arquitectos de Chile, 1978, n² 22, p. 11-13.

Ribera, E. Casas, habitación y espacio urbano en México. De la colonia al liberalismo decimonónico. Scripta Nova. Revista electrónica de geografía y ciencias sociales. Barcelona: Universidad de Barcelona, 1 de agosto de 2003, vol. VII, núm. 146(015). <http://www.ub.es/geocrit/sn/ sn-146(015).htm> [ISSN: 1138-9788].

Rodrigues Soares, P. e Hidalgo, R. El Estado y la vivienda popular en la ciudad latinoamericana. El caso de Brasil y Chile (19361967). En VIII Simpósio Nacional de Geografia Urbana. Recife: Universidade Federal de Pernambuco, 2003.

Sahady, A. Invariantes de una arquitectura reconocible: la vivienda colonial urbana en Chile. Boletin de Instituto de la Vivienda, 1996, no 29, p. 24-33.

Stabili, M. El sentimiento aristocrático. Elites chilenas frente al espejo (1860-1960). Santiago: Editorial Andrés Bello y Centro de Investigaciones Diego Barros Arana, 2003.

Sabatini, F., Cáceres, G. y Cerdá, J. Segregación residencial en las principales ciudades chilenas: Tendencias cle las tres últimas décadas y posibles cursos de acción. EURE, 2001, 120 82, p.21-42.
Tagle, E. Venta de edificios por pisos o departamentos. El Mercurio, lunes 23 de agosto de 1937.

Torres, H. Cambios socioterritoriales en Buenos Aires durante la clécada de 1990. EURE, 2001, vol. 27, n' 80, p.33-56.

Thuillier, G. Gated Communities in the Metropolitan Area of Buenos Aires, Argentina: a challenge for Town Planning. Housing Studies, 2005, vol. 20, $17^{\circ} 2$, p. 255-271.

Vidal Koopmann, S. Countries y barrios cerraldos: nuevas formas de segregación urbana. Unáa aproximación al temá del crecimiento en el área metropolitana de Buenos Aires (Argentina). Geodemos, 2003, ñ 6, p. 97-118.

Vidal Koopmann, S. Ciudades amuralladas: la paradoja urbana de la globalización. En A. GUIANCE (Comp.) La frontera: realidades históricas, sociales, políticas y mentales. Buenos Aires: Biblos, 2005 (en prensa).

Viclal Koopmann, S. y Dietrich, P. La reestructuración de las áreas metropolitanas en América Latina. El caso buenos aires: inequidad social y fragmentación territorial. En Anais do X Encontro de Geógrafos da América Latina São Pálulo: Unive1sidade de Sào Paulo, -20 a 26 de marrço de 2005, p. 16236-16259.

Villavicencio, I. y Durán, A. M. Treinta anos de vivienda social en la Ciudad de México: nuevas necesidades y demandas. Scripta Nova. Revista electronica de geografia y ciencias sociales. Barcelona: Universidad de Barcelona, 1 de agosto de 2003, vol. VII, núm. 146(028). <http://www ub.es/geocrit/sn/sn146(028).htm> [ISSN: 1138-9788].

Wilhelmy, H. \& A. Borsclorf. Die Städte Südamerikas. 2 vol. Berlin, Stuttgart: Gebr. Bornträiger, 1984. 